\title{
Factors and there Influence on Employee Retention of the Apparel Sector Employees in Anuradhapura district.
}

\author{
PGRB Chandrasekara* \\ *Graduate, B.Sc Business Management Special, roshanthabuddhika333@gmail.com \\ Department of Business Management \\ Rajarata University of Sri Lanka \\ DOI: 10.29322/IJSRP.10.07.2020.p10358 \\ http://dx.doi.org/10.29322/IJSRP.10.07.2020.p10358
}

\begin{abstract}
Employee retention is critical for organization because employees are the driving force to achieve the development and accomplishment of the organization's goals and objectives. Retention starts at the very early stages of the recruitment process. It is a never ending process as retention is affected by almost all aspects of the business and directly affecting the employee/ employer relationships around the world. To enhance employees' retention, the literature recommends that so many factors play an important role in the retention of employees in the organization. Thus, the purpose of this study is to investigate the relationship between employee retention and the four main predictors namely, motivation, work environment, primary hygiene factors and secondary hygiene factors of Rich Light Exports (pvt) Ltd in Anuradhapura District. With a thorough review of the literature, conceptual model was developed. The study developed validated research instruments. The model was empirically tested by collecting data from apparel sector employees' in Anuradhapura District. A total of fifty Rich Light Exports (pvt) Ltd employees were selected for the study using the stratified random sampling technique and fifty usable questionnaires were returned. To measure the factors influence on employee retention, descriptive analysis were used and mean and standard deviation was tested. Hypotheses were developed and to test hypotheses, Pearson correlation coefficient analysis was used with the support of Statistical Package for the Social Sciences (SPSS). In connection with first objective, findings of the study revealed that all most all factors had high mean value that represents all factors were highly influence on employee retention. Regarding second, third and fifth objective, the results showed that motivation, primary hygiene and secondary hygiene have strong and significant positive relationship on employee retention. Likewise, work environment have a positive relationship but very weak relationship on employee retention. Further, this study provided conclusion of the results and recommendations for Rich Light Exports (pvt) Ltd in Anuradhapura District to enhance the level of employee retention.
\end{abstract}

Keywords: Motivation, Retention, Primary Hygiene, Secondary Hygiene, Work Environment

\section{Introduction}

Employee retention is critical for organization because employees are the driving force to achieve the development and accomplishment of the organization's goals and objectives. Retention starts at the very early stages of the recruitment process. It is a never ending process as retention is affected by almost all aspects of the business and directly affecting the employee/ employer relationships around the world. Regardless of the region, recruitment process and retention seem to take the biggest hits. Retaining key employee is a vital source of competitive advantage for any organization. A concept of retention is critical to ensure a highly productive workforce. It is no use having good personal if they are just as likely to leave, and there is little utility value having employees retained in the organization if they do not engage with the organization and what it do (Smith, 2004).

Retention of employees is very important for an organization but it is affected by number of factors. So, it is important to address these factors otherwise, the organization will be affected by high employee turnover. In organizations, there are always some star performers who are better than average employees. Organizations must have some retention strategies to retain especially such star performers. If they leave the organization they will leave with their experience and that can be very attractive to their competitors and headhunters always look for this kind of experienced employees. A successful marketing manager can be very desirable to the competitors of that particular company. When an organization loses this kind of an employee, it brings negative effects on the consistency for maintaining the same productivity and it creates a negative impact on the organization's goodwill. Organizations are need to create such an environment that employees would remain happy and willing to stay. That will help the 
organization to create and sustain a competitive advantage in this competitive world. It is proved that humans are the most valuable resource and; talent is the critical success factor for any organization.

Organizations must identify the factors for each efficient employee, because every factor does not have the same impact on employees. If a manager wants to reward the competent employees for their outstanding performance, he needs to know what motivates them the most. To develop a competitive advantage in a global economy, organizations must support the strategic plans and required actions for employee retention. A number of studies have Ryan, Deci, \& Connell, (1989) found where retention factors such as intrinsic, extrinsic, working environment, benefits etc., were predefined based on some criteria and an attempt was made to identify how much they impacted on retaining an employee.

In this study, Researcher aimed to identify the factors that influence employee retention and will suggest these for successful retention policy in the context of Rich Light Exports (Pvt) Ltd in Anuradhapura district.

\section{Problem Statement}

In today's scenario organizations take a proactive measure to formulate the retention strategies. Employee Retention Strategies helps organizations provides effective employee communication to improve commitment and enhance workforce support for key corporate initiatives. Organizations attempt towards building up of the work environment, focusing on employees, their morale, motivation, satisfaction and ability and willingness to be highly productive but still the attrition rate is quite high. Every organization has almost similar retention policies and strategies, but the influence of these retention factors implied by the employer differs from organization to organization. Thus, it is very essential or crucial to understand and identify the most influencing retention factors, according to the expectations of the employees.

Hence, the current study is mainly focused on testing the factors and relationship between employee retention and the four main predictors and the selected apparel industry employees who were the respondents of this study. It is obvious that there exists a gap in literature to examine the factors and the relationship with selected variables on employee retention, especially in the context of Anuradhapura district.

Based on the above discussion, the research problem of the study is presented as follows;

The problem of this study is to investigate "what are factors and whether there was a significant relationship between employee retention and the four main predictors namely, motivation, work environment, primary hygiene factors and secondary hygiene factors in selected Rich Light Exports (Pvt) Limited employees in Anuradhapura District".

\section{Research Questions}

1. What are the factors influence on employee retention in Rich Light Exports (Pvt) Limited in Anuradhapura District?

2. Is there any relationship between motivation and employee retention in Rich Light Exports (Pvt) Limited in Anuradhapura District?

3. Is there any relationship between work environment and employee retention in Rich Light Exports (Pvt) Limited in Anuradhapura District?

4. Is there any relationship between primary hygiene factors and employee retention in Rich Light Exports (Pvt) Limited in Anuradhapura District?

5. Is there any relationship between secondary hygiene factors and employee retention in Rich Light Exports (Pvt) Limited in Anuradhapura District?

\section{Research Objectives}

- To find out the factors influence on employee retention in Rich Light Exports (Pvt) Limited in Anuradhapura District.

- To investigate the relationship between motivation and employee retention in Rich Light Exports (Pvt) Limited in Anuradhapura District.

- To investigate the relationship between work environment and employee retention in Rich Light Exports (Pvt) Limited in Anuradhapura District.

- To investigate the relationship between primary hygiene factors and employee retention in Rich Light Exports (Pvt) Limited in Anuradhapura District.

- To investigate the relationship between secondary hygiene factors and employee retention in Rich Light Exports (Pvt) Limited in Anuradhapura District. 


\section{Significance of the Study}

Retention is a voluntary move by an organization to create an environment which engages employees for a long term. The main purpose of retention is to prevent the loss of competent employees from leaving the organization as this could have adverse effect on productivity and profitability.

This study is therefore necessary since it seeks to establish the retention of employees. Findings and recommendations will help to ensure the much needed industrial harmony for growth and development in the country. Researcher expected to provide new solutions and evidence on the usefulness of segmentation techniques for human resource management and retention factors which are in favor of employee.

In addition to that academicians, the study would act as guidance to other researchers who will be attracted to conduct further study related to factors influence in employees retention in Rich Light Exports (Pvt) Limited in Anuradhapura District. Through this study entrepreneurs can identify what are the areas that they want to pay attention to grow their business .So this study is important to both economy and entrepreneurs. The results of this study will be disseminated via this report thus it will contribute to the stock of knowledge.

\section{Limitation of the Study}

Given the explorative nature of the study, some limitation of data should be stated. The research focused attention on the impact on retention of employees. Though the study covered production level employees of Rich Light Exports (Pvt) Limited in Anuradhapura District.

- Study was limited to production level employees only in three production lines and also, excluded the management staff of the organization.

- Due to limited time and resources only 50 respondents were drawn out of workforce of 600 working staff.

- Respondent took a longer period of time to complete the questionnaires as they were most times busy with their work. Thus leading to a delay in the collection of data.

- The responses received from participants may not $100 \%$ accurate due to subjectivity and personal biases.

\section{Literature Review}

According to Sue (2001) in simple terms, employee retention means keeping those members of staff that one wants to keep and not losing them from the organization, for whatever reason but especially to competitors. To Sue, organization needs to have right people with the right skills and abilities in the right place and at the right time. This relies on planning, effective recruitment, selection, training, development and retaining those you want to keep. Some of the most pressing human resources management issues in organization today center on the need to effectively obtain high performing employees which will accordingly increase productivity and profitability.

To Sue (2001) employee retention is synonymous to employee motivation. A motivated employee will be satisfied and therefore more productive and more likely to stay within the organization all other things being equal. Therefore, a key issue to address when looking to retain employee is to motivate them. Employee retention can determine the success of the organization or otherwise. If the best staff is not retained then the organization cannot retain its key clients and customers. Keeping valuable employees can be a source of competitive advantage. An organization needs to attract good people, use them effectively and reward them so it can keep the staff it wants. It costs money to keep them but failing to deal with employee retention can potentially affect the financial performance, and reduce the organization's profit. In a service delivery organization, people tend to lose their trust in the organization and its integrity suffers.

Smith (2004) also indicates that successful organizations realize employee retention and talent management are integral to sustaining their leadership and growth in the market place. Smith asserts that becoming an employer of choice by attracting, hiring and retaining high caliber employees in today's labour market are the things that challenge organization to manage talents and skill at all levels in the organization. It is always wiser and less expensive to retain employee than to be recruiting. According to Smith (2004) employee retention has become one of the most critical issues facing corporate leaders. This has come about as a result of the shortage of skilled labour, economic growth and employee turnover. Workforce stability is an issue because of unprecedented churning in the employment market with a focus on retaining one's employees. Today's labour force is different, therefore managers must take responsibility for their own employment retention, and if they neglect this critical management role, they could be left without enough good employees. 
To Smith (2004) a wise employer will learn how to attract and keep good employees. He has observed that money and benefits may bring employees through the front door, but poor working conditions and poor management skills drive them out the back. When it comes to recruiting and retaining many organizations fail to see their own bad habits, faulty processes and other inefficiencies leading to low productivity and high turnover. Reduced turnover gives an organization more stability, which pleases employer, employees and clients alike. A satisfied workforce reflects positive attitude towards others. They in turn will reflect a positive attitude towards clients and thus generating higher satisfaction which grows the revenue of the organization. Employee retention is one of the primary measures of the health of an organization. If you are losing critical staff members, you can safely bet that other people in their departments are leaving as well. Exit interviews with departing employees provide valuable information you can use to retain remaining staff.

Retention of excellent employees is one of the most important challenges in organization today. Retention requires a competitive salary and great benefits. However, retention of an organization's best employees requires a whole lot more. Employee's involvement, recognition, development, advancement and pay based on performance just get the organization started in their quest to retain their best. What do people want? The same things they have always wanted is challenging and stimulating work, fair pay, the tools and resources needed to do their jobs, recognition for work well done and involvement in the decisions that impact their day to day lives at work (Grensing, 2000).

\section{Factors affecting to Employee Retention}

Amaram (2005), investigated; leaving the organization is a mental decision of the employees. Turnover is a psychological outcome of the intention to quit or to remain with the firm. When the labour market is volatile, it has been observed that the retention of the best employees is done by the companies. With high demand in the labour market retention becomes an important strategy in order to survive in the competitive marketplace. There are two types of cost, direct and indirect cost of the uncontrolled labour turnover, which, if not considered can create a huge loss for the organizations. Hokanson et al. (2011) in his study, has shown the importance of some organizational characteristics (internal career opportunities, size, organizational climate etc.) and environmental variables (available employment alternatives, economic and market conditions, etc.) which highly affect the turnover rates. A company's reputation also helps a lot in retaining the best employees of the organization.

As stated by Herzberg et al. (1959) HR managers are facing a big challenge for to reduce the employee's intention for a turnover. The various motivational techniques used by the employers are of no use these days. These practices are treated to be an old practice followed in today's fast-moving environment. It is observed that turnover intention has a great influence on attrition factors for e.g. Work-life balance, flexible working hours etc. It has been observed that human resource management should be practiced not only at the strategic level, but at every day to day level. This helps in making the employees know and understand the policies of the organization. HR should look at the problems of the employees and must solve them creatively.

According to Srinivas (2012) training and development program should be organized for the employees. Training in areas like quality of work, job-related, technical etc. should be provided by the employer so that the employees get a feeling that not only the organization is growing, but also the employee in themselves are growing and developing their skills. Employees who are not satisfied with the training programs should not be left unattended. The reason behind their dissatisfaction should be identified and should be worked on. Since the technology and management practices are changing at a fast rate, training the employees and updating them has crucial. A training program is needed to develop their skills, attitudes and behaviour. Training programs should be evaluated after its completion as it helps in identifying the limitations and drawbacks.

McKeen et al (2009) stated that the importance of IT staffing practices in hiring, retention, career development and training, and performance, promotion and succession planning. The IT profession is unique in it; although the world is witnessing development in the technology, but the old technology never seems to go away. Today, organizations are also found to be using the older languages to operate systems and applications which are coded in the old languages. This confirms that as long as the organizations are using the older technology, people with experience of old technology are required by the organization.

The study of motivation is concerned with why people behave and think the way they do. Motivation is a highly complex concept that influences and is influenced by a large number of factors in the organizational environment. A number of definitions for motivation are presented in the literature. Mathias and Jackson (2002) look at motivation as the complex forces, drives, needs, tension states or other mechanisms that start and maintain voluntary activity directed towards the achievement of personal goals. Campbell and Pritchard (1976) define motivation as a set of independent and dependent relationships that explains the direction, amplitude and persistence of an individual's behavior holding constant the effects of aptitude, skills, understanding of a task and 
the constraints operating in the work environment. According to McClelland (1961) individuals tend to develop certain motivational drives on the cultural environment in which they live and these drives affect the way people view their jobs.

Thomas et al (1990) added that there is evidence supporting the existence of a linkage between an employee's motivational level and their individual performance. A motivated employee is a loyal employee and to be loyal implies that the employee supports the actions and objectives of the firm. Martin Bruce (1962) stated that the appearance of the job as a whole has, in fact a bearing on the willingness and quality of an employee's performance. Porters and Steers (1991) in their study added that individuals have a number needs, desires and expectations in varying strengths and based on these needs and expectations, people act in certain ways which they believe will lead to a desired goal. This implies that the individual is provided with a feedback about the impact of their behaviour and this in turn may reassure the individual if their current way of acting is correct or not. In addition, they pointed out that the selection of certain motives over others, as well as the intensity with which such motives are pursued, may differ from person to person. The definitions and arguments reveals different perceptions about the concept of motivation, however in summary, motivation is perceived to be purposive, goal directed, and energizes human behaviour.

McKeen et al. (2009) found that people with higher education do not stay for a longer period of time with one organization, as they have a lot of opportunities in the market. It becomes easy for these types of employees to get another job and hence while recruiting, HR do go back and check on the stability of the employee. Education does play a role in letting the employees decide whether to stay with the organization or to leave it for a better opportunity. Attrition is dependent on the education factor as well, said (Sandhya \& Kumar, 2011). Rewarding employees is important to retain them. Rewarding specifically on the knowledge, skills, abilities and attitudes is a good way to reduce the attrition rate. By making these employees feel attached to the organization. McKeen et al. (2009), stated that training employees with not the required skills, but also about different domains help in retaining the best talent pool. Be it any industry, pay is the factor that actually controls the attrition rate at the entry level of the organization. Employees with less experience, consider it very easy to leave the organization. They are the ones who actually need to be looked into in order to reduce the attrition rate.

When an employee is honoured, he or she stays for a longer period of time. Remuneration also matters, if the organization is not paying as per industry standards the chances of losing the employees increases. Hee and Ling (2011) said that today it's not only about maintaining the industry standards but also about what additional does the organization do to retain the employees. Paying as per industry standards is good but something additional is required so that the employees can compare with the other organizations and this additional effort influence or force them to stay with the current organization. Radford and Chapman (2015) stated the rate at which promotion is given to the employees may act as a catalyst for retaining the employees. Along with pay if a minimum duration is followed for giving promotion, chances for the employees to stay with the organization increases. It was observed that whether an employee stays or leaves the organization depends on the actions taken by the firm. Organizations should consider approaches to different management practices like flexible working hours, competitive rewarding systems, innovative benefit plans, and inspiring reformation etc. The employer should build an effective work environment which motivates the employees to stay with the employer for a longer period of time. Robbins (2003) stated that working environment is one another factor that needs to be considered for the benefit of the organization. It helps in retaining the employees in more and effective way. Working environment and the culture of the organization influence a lot to retain the employees.

According to Daniel and Metcalf (2009) recognition is a return on an employee's effort and dedication at work, as well as his or her results. An employee recognition program can be a great morale-building tool for any organization, whether large or small. An effective recognition programme can lead to innovation, higher productivity and greater job satisfaction for the workers (Beer and Walton,2014). Employee recognition programmes could include several levels of recognition, from a simple Certificate of Appreciation to Employee of the Month to awards given on the division and companywide level, recognition should be provided to those who exceed expectations and earn the award (Steers and Porter, 2011). Recognition is one of the strong motivation factors; employees feel comfortable when they are praised and recognized (Armstrong, 2007).

A recognition programme can help employers meet their organizational goals by helping attract and retain high-performing employees. Daniel and Metcalf (2009) reported that companies are aligning their employee recognition programmes directly to the strategies of the organization due to the following nine reasons listed according to order of importance a) Create a positive work environment b) Creating a culture of recognition c) Motivating high performance d) Reinforcing desired behaviours e) Increasing employee morale f) Supporting the organization mission and vision $\mathbf{g}$ ) Increasing retention and decreasing turnover $\mathbf{h}$ ) Encourage loyalty and i) Supporting a culture change. Other reasons for adapting a recognition programme includes: reducing costs, retaining key employees, increasing employee productivity, competitiveness, revenues and profitability, improving quality, safety and customer service, and lowering stress, absenteeism, and turnover (Daniel \& Metcalf, 2009). 
Kay and Jordan (1999), stated that it takes time for the team member to settle with the new member and increase the productivity level. Even after being trained the new employee needs the other team members help to understand the process and match their speed of working? PR costs is another a big cost bared by the organizations in order to answer the reason for the voluntary and involuntary attrition. In the exit interviews employees very clearly state that they are leaving their current employer because of the pay or remuneration and as the other company is paying them more than the current employer (Samuel \& Chipunza, 2009)). When the economy is doing good there is always a high number of opportunities in the market. Employees perceive that if the organization is not doing well or if any news comes up which is spoiling the reputation of the organization then the employees look for other opportunities as the employer itself is not certain about how long will it survive in the near future. Varma (2011)), in his paper established that organizations should also elicit a sense of commitment towards the employees then only employees can develop a faith and be loyal to the organization. For creating employee satisfaction among the employees, a good working culture, strength of leadership, development of shared goals is needed to be developed by the employer. These factors influence the indices of employee satisfaction in any organization. Many organizations do not consider that a repetitive and unattractive job can become boredom for the employees and after 6 to 9 months employees start losing interest in their jobs. Hence employer should make the job interesting by removing repetitiveness from their day to day job.

Surviving for a longer period of time depends on these key workforces. Externally customer satisfaction is important and internally employee's employee satisfaction is crucial. Both of them are directly related because if the employees are satisfied with the recognition and reward given by the organization based on their performance, a better and better customer support and satisfaction will be provided by the employees. A satisfied employee always tries to satisfy the customer of the organization and also to increase the number of loyal customers. According to Das and Baruah (2013) retention is basically a process in which the employer tries to encourage the employees to stay for a longer period of time. The attachment of the employee with the organization depends on many factors or variables which is important to identify and study their criticality. Both the retention process and the quitting or attrition process should be studied and researched simultaneously as this may give the employers an idea about the expectation of the employees from the organization. HR personnel should make a note of the reasons why the employees are leaving their organization and why some of the candidates want to join their organization. Analysing both of these areas may give the employer a clear picture as to where the loop-hole is exactly.

A high amount of risk is associated with the attrition rate in any organization as the human capital cost will be very high to be bared. The skilled employees once leave their current employer do get hired by the competitors and due to this the current employer not only loses on the employee but also the knowledge and information about the organization to the competitor. Since the competition to survive in the marketplace is growing organizations cannot afford to lose the employees and the information about the organization. This may bring a lot of harm to the organization. Hence the other way to stop this to happen to avoid these situations is to formulate the retention strategies in such a way that the thought of leaving the employer comes to the employee's mind only when he or she is facing some unpredictable personal problem which is inevitable. It was said by Varma (2011) that the reason for high turnover rate faced by any organization is it private or public is because of poor human capital policies, substandard recruitment policies, imperfect supervisory practices and mediocre grievance procedure.

Employees are considered as the long-term investments for the organizations and management should treat them in that way by redesigning their job, giving promotions to the hard working and best performers, recognizing the best performers, creating a sense of belongingness among the employees etc. Every organization is trying their level best to retain their best and skilled employees but still there are some reasons which lead to attrition of the employees said (Das \& Baruah, 2013). Organizations are trying to give the best facilities possible but at times these facilities also fail to retain the employees. Employers find it difficult to understand and identify the major reasons for why employees quit their jobs even after being provided with good retention policies and strategies. Satisfying the human resources are the biggest and the toughest job of the HR personnel's. As every individual is different from each other understanding their mindset and thoughts are very difficult and challenging.

Although there are some very important and crucial factors and variables that do impact the retention of employees, still the other factors which do not influence retention to a great extent should not under-estimated. Every factor should be given equal importance while framing the retention strategies and implementing it in the organization. None of these factors can be overlooked. Kumar et al. (2014), in their research work studied the motivation factor for retaining the employees. The found that this factor can actually help the employee to perform better and which can overall improve the performance of the organization. It was stated that some of these strategies like open communication policy, reward programs, career development programs, performance based bonus etc. can act as a motivation for every employee in the organization. The employee retention program is a program that helps the employer to retain the employees for a longer period of time (William \& Werther, 1996). It encourages and supports employees to remain with the employer as the employer is taking care of their desires, needs and career. 
It is always said that HR personnel should hire the right person for the right job and at the right time but to encourage the employees and to retain them for a maximum period of time is difficult and challenging for the HR personnel. Employees who have talent will never sit back without a job; they have a lot of opportunities available in the market. Employees switch their job according to their choices when they are not satisfied with the organization. Successful organizations are at the top of the list as they take care of their employees and consider them as the important asset of the organization (Imtiaz et al., 2013). An organization that considers human capital resource as the crucial and important resource and works for the satisfaction and benefits of their human resource are the ones who survive and thrive in this competitive environment. Employees leave the organization due to personal and professional reasons, which the employer needs to, identify and work on it, to the extent they can control these factors.

Herzberg et al (1959) categorized motivation into two factors, motivator and hygiene. Motivator factors are intrinsic to the job content and responsible for adding meaning to the work. It comprises of factors like feeling of achievement, prospects of career growth, increased responsibility, decision taking roles, interesting work, rewards and recognitions etc. It is important to understand that absence of motivation doesn't lead to dissatisfaction, but their presence certainly causes satisfaction. The Hygiene factors are the needs that are required for employee satisfaction and their elimination would certainly result in lack of motivation or dissatisfaction. However, even when they are adequately present, the employee's level of motivation is only neutral. These factors include pay, working conditions, supervision, job security, HR policies, work schedule, paid leaves and interpersonal relationships. Motivators are stemming from the intrinsic context of a job whiles hygiene are stemming from the extrinsic context of the job. The key difference between motivator factors and Hygiene factors is that whereas motivators bring about positive satisfaction, hygiene factors try to prevent dissatisfaction.

The understanding of this theory is that even if motivators are absent and hygiene factors are provided for, workers will still not be satisfied with their jobs likewise will it be if motivator factors are provided and hygiene factors are not available, workers will show signs of dissatisfaction. Both must be available to bring about satisfaction and prevent dissatisfaction respectively. Fredrick Herzberg's theory suggests that two motivating factors govern behaviour: those that increase an individual's overall satisfaction and hygiene factors that provide no satisfaction, but create severe dissatisfaction if absent. This theory differentiates between behavioral needs, describing the reasons why employees need specific things and allowing a manager to better direct their motivation. Herzberg's Theory can be applied by managers to motivate employees. By identifying the hygiene factors, managers can fulfill the basic needs of employees and remove any element of dissatisfaction. When employees have no dissatisfaction arising from the job environment, they are in a better mode to be motivated. By applying the theory, employees can be motivated by fulfilling their esteem and self-actualization needs. This includes a sense of achievement when they have performed their jobs satisfactorily. Therefore, managers can fulfill this need by improving job content.

Also, certain hygiene factors are motivators to some individuals. Take for example money. Money is a hygiene factor, based on Herzberg's Theory, but it is a motivation for a lot of employees. It motivates them to work harder in order to gain recognition, which translates into a higher salary. Herzberg's Theory parallels Maslow's Hierarchy of Needs, thus making it easier to apply. However, the methodological bias that exists makes the theory questionable to some extent. Managers can apply the theory to motivate employees by identifying the hygiene and motivation factors. Individual differences must still be taken into account because not every employee would appreciate this method.

A salary is a form of payment from an employer to an employee, which may be specified in an employment contract. It is contrasted with piece wages, where each job, hour or other unit is paid separately, rather than on a periodic basis. From point of view of running a business, salary can also be viewed as the cost of acquiring and retaining human resources for running operations and is then termed personal expense or salary expense. In accounting, salaries are recorded in payroll accounts. Salary is fixed amount of money or compensation paid to an employee by an employer return for work performed. Salary is commonly paid in fixed intervals, for example, monthly payments of one-twelfth of the annual salary. Salary is typically determined by comprising market pay rates for people performing similar work in similar industries in the same region. Salary is also determined by leaving the pay rates and salary ranges established by an individual employer. Salary is also affected by the number of people available to perform the specific job in the employer's employment locale. Salaries are fixed cost in nature.

Work Place Environment Workplace environment includes not only the physical elements around the work area of an employee but also all things that form part of the employee's involvement with the work itself. World at Work, the Total Reward Association defines workplace environment as the total cluster of observable physical, psychological and behavioural elements in the workplace. A positive work environment is believed to make employees feel good about coming to work and provide the necessary motivation to sustain them throughout the day. This observation is echoed by Wells \&Thellen (2002), who stress that organizations offering suitable levels of privacy and sound controls at the work place thereby improving levels of motivation and 
commitment in employees have an increased ability to satisfy and retain employees. Heneman (1999) also does allude to the fact that one of the most crucial element of any organizations total reward strategy is having a positive work environment.

\section{Methodology}

\section{Conceptual Framework}

Figure 3.1 Conceptual Framework

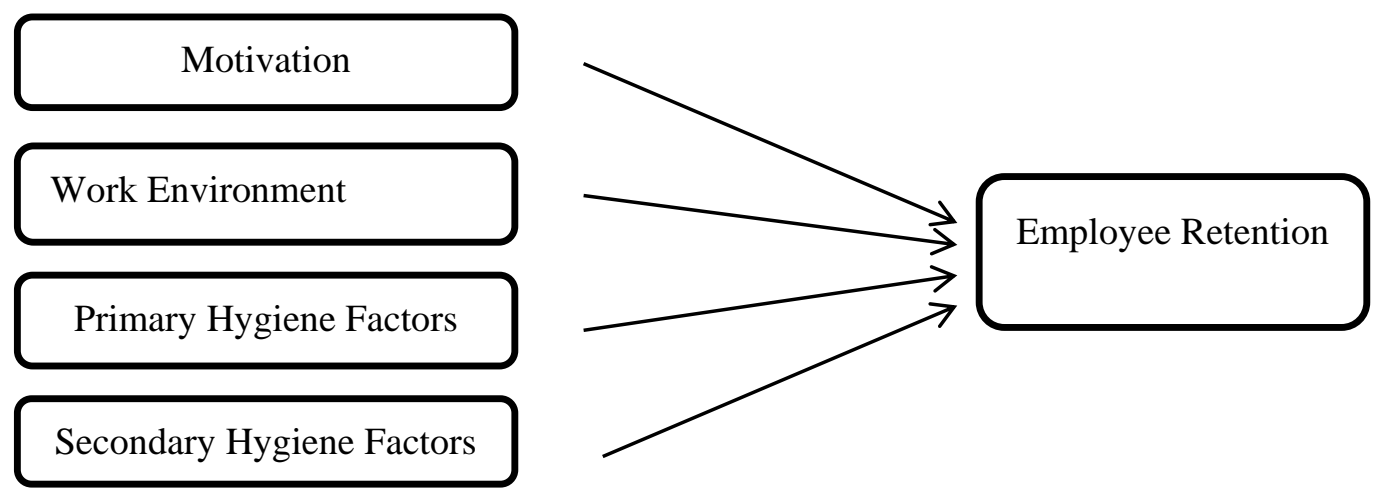

(Source: Developed by the Researcher)

This conceptual framework was developed to show the variables which are involved in the measuring the employee retention. In so for as this study find the factors influence on employee retention in Rich Light Exports (Pvt) Ltd in Anuradhapura district with the help of four variables mentioned above. The above figure gives conceptualization framework to measure the factors and relationship on employee retention.

As indicated in Figure 3.1 and discussed in chapter 2, based on the discussion the following hypotheses were formulated to achieve the second research objectives of this study.

$\mathbf{H}_{1}$ : Motivation will be positively correlated to employee retention

H2: Work Environment will be positively correlated to employee retention.

$\mathbf{H}_{3}$ : primary hygiene factors will be positively correlated to employee retention.

$\mathbf{H}_{4}$ : Secondary hygiene factors will be positively correlated to employee retention.

\section{Operationalization of variables}

\begin{tabular}{|c|c|c|c|}
\hline Concept & Variables & Indicators & Measurement \\
\hline $\begin{array}{l}\text { Factors influencing the } \\
\text { Retention of Employees } \\
\text { in the Apparel Industry. }\end{array}$ & Motivation. & $\begin{array}{ll} & \text { Career Growth. } \\
\text { - } & \text { Job Security. } \\
\text { - } & \text { Healthy Workplace } \\
& \text { Environment. } \\
\text { - } & \text { Pay Scale. } \\
\text { - } & \text { Promotion } \\
& \text { Opportunities. }\end{array}$ & Likert Scale \\
\hline
\end{tabular}




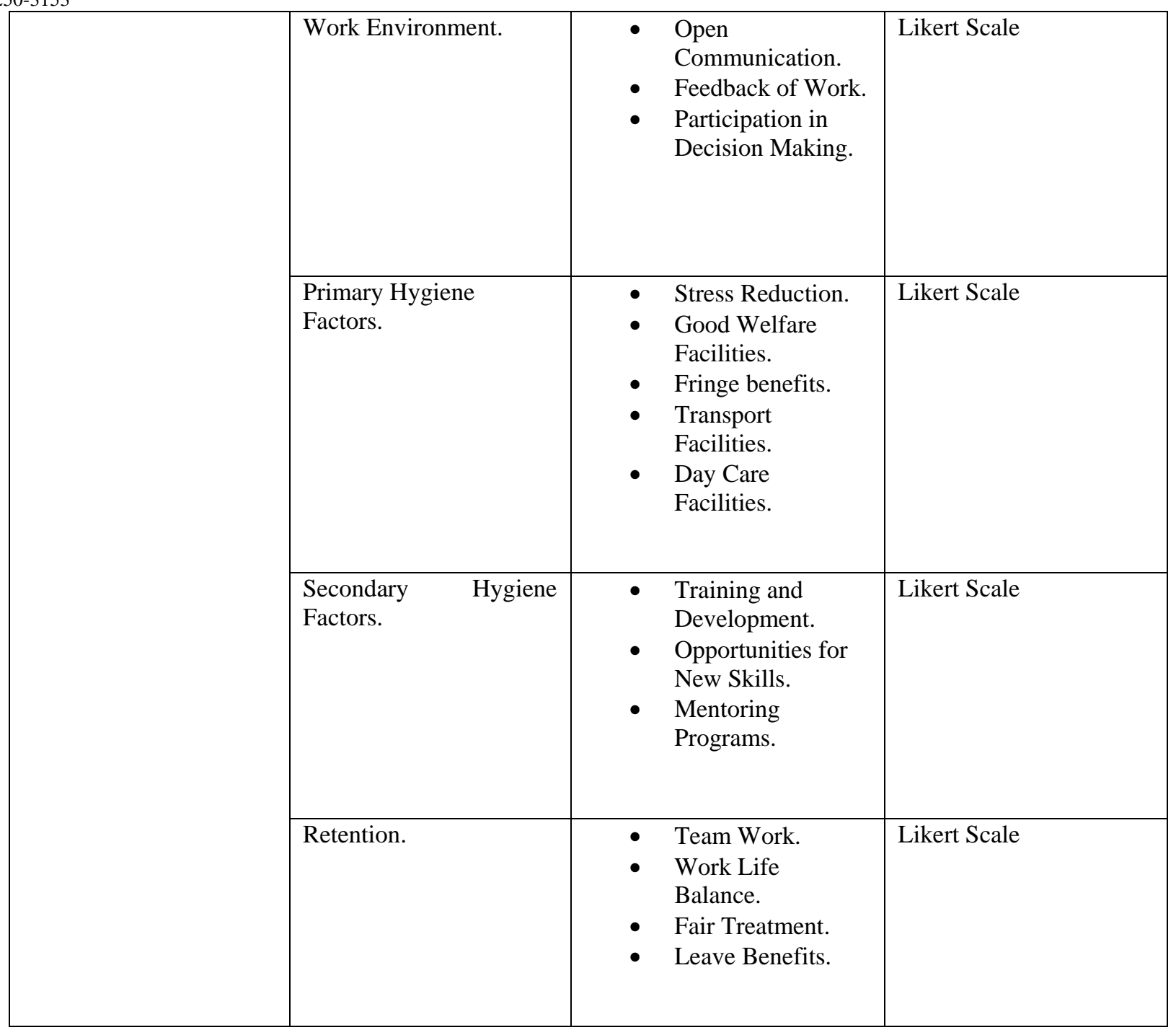

\section{Research Methodology}

Methodology refers to general principles which emphasize how to investigate the social world and how to demonstrate that the knowledge generated is valid. Kelly (2004) explained that collection of philosophical and theoretical commitments may influence decisions made about the research design and the choice of specific methods of data collection and analysis. Further, there are two types of approaches used in researches such as inductive approach and deductive approach. Inductive approach is mostly concerned with the generation of new theory emerging from the data and focused on exploring new phenomena and apart from this. Deductive approach usually begins with a hypothesis and is usually used in research questions to narrow the scope of the study. Therefore, current study adopted deductive approach and to get the most reliable findings, quantitative method is used for this research. Malhotra (1993) defined quantitative research method as a research methodology that seeks to quantify the data, and typically it applies some form of statistical analysis. In this regard, Cavana, Delahaye, \& Sekaran (2001) argued that to obtain the valid finding about the relationship between variables; researchers should develop a planned procedure for gathering and interpreting data. Therefore, the current study is to develop a theoretical frame work to investigate the relationship between employee retention and the four main predictors such as motivation, work environment, primary hygiene factors and secondary hygiene factors based on previous literature.

\section{Research design}

Research design is a way that the requisite data can be gathered and analyzed to work out a solution (Sekaran, 2003). The purpose of the study is to find out the factors and test the hypotheses in order to achieve the research objectives, which are, to investigate the relationship between dependent and independent variables. A study can be conducted either in contrived or non-contrived settings; this study is non-contrived (natural). It could be carried out in a natural environment where things or events which are studied occur normally. Further it is a field study. The extent of researcher interference was minimal since the study was carried 
out as a field study. When the researcher is interested in delineating the important variables associated with the problem, the study is called a correlational study" (Sekaran, 2003). The type of investigation of this study is a descriptive and correlational study.

Since this research studies a particular phenomenon at a particular time, it is a cross sectional study. As per Rose et al, (2015) a cross sectional study is used to address a range of research questions where the focus is on the current state of the phenomenon of interest and according to Sekaran \& Bougie, (2010), the data are gathered just once, perhaps over a period of days or weeks or months, in order to answer a research question. Sekaran, (2003) stated that the unit of analysis refers to the level of aggregation of the data collected during the subsequent data analysis stage. The unit of analysis of this study is the individual employee who is working in Rich Light Exports (Pvt) Ltd in Anuradhapura district.

\section{Population and sample for the study}

According to Burns and Bush (2009) population is the entire group under study as specified by the research objectives. Thus the study population comprised of all the individual employees of selected Rich Light Exports (Pvt) Ltd. Moreover, the respondents are classified based on their sections or units such as, value added section employees, production unit employees and brand unit staff.

Further, employees of selected Rich Light Exports (Pvt) Ltd which are generally referred a Pioneer Association of the apparel export industry in Sri Lanka inaugurated in 2004 and Sri Lanka Directory of exports. Therefore, the target populations of this study were all the relevant units' employees who were working in Rich Light Exports (Pvt) Ltd.

According to Burns \& Bush (2009), sample is the subset of a population that suitably represents the entire group. Based on the proportion of employees the sample was selected and the data were collected from 50 respondents. The stratified random sampling method was used to administer the questionnaires to the respondents who represented the Anuradhapura District based on a proportionate basis.

\section{Sample Study}

\begin{tabular}{|c|c|c|c|}
\hline $\begin{array}{l}\text { Categories Based on } \\
\text { section }\end{array}$ & Total Population & $\begin{array}{c}\text { Percentage }(\%) \text { of total } \\
\text { staff }\end{array}$ & Sample \\
\hline \multicolumn{4}{|l|}{ Value Added services } \\
\hline - $\quad$ Sewing & 400 & 67 & 34 \\
\hline - $\quad$ Printing & 50 & 08 & 04 \\
\hline - $\quad$ Cutting & 100 & 17 & 08 \\
\hline Production staff & 50 & 08 & 04 \\
\hline Total & 600 & 100 & 50 \\
\hline
\end{tabular}

(Source; Developed by the Researcher)

Research studies can use a number of methods to collect data such as self- administered questionnaires, or individually administering questionnaire. In the current study, the data were collected from the 50 respondents through a personally administered structured questionnaire. The respondents were employees of the Rich Light Exports Private Limited. The benefit of this method according to Cooper and Schindler (2003) is said to be good cooperation from participants and interviewer was able to reach even those participant who explained communication barrier of various forms. This method permitted the researcher to gain deeper insights into the perception of transfer of training factors. The data was collected from different section in the Rich Light Exports Private Limited.

The questionnaire consisted of two sections; Part I: demographic information and Part II: research information that included items of motivation, work environment, primary hygiene factors, secondary hygiene factors and employee retention. All questions in Part I on demographic information of the questionnaire were developed by the researcher. Questionnaire items of Part II were developed by the researcher as well as few items already developed research instruments on employee retention by researcher Nancykumari (2018). To measure the part II , the researcher used 23 items and respondents were asked to indicate the response from numbers 1 to 5 for each statement. The researcher had used 5 point Likert scale.

\section{Five-Point Likert Scale}


1. Strongly disagree

2. Disagree

3. Neither agree nor disagree

4. Agree

5. Strongly agree

\section{Data Analysis Techniques}

The data obtained from the survey questionnaire were carefully coded and checked for consistency and entered into the SPSS spreadsheet. The analysis was performed with SPSS ver.21. Descriptive statistics was employed to analyze data and the results were tested with parametric and non-parametric tests of significance. Besides, measures of central tendency (mean, standard deviation) were used to analyze the questionnaire survey result. To conduct documentary analysis SPSS ver. 21 was used to run the Pearson correlation between the independent factors and dependent factor. Measures of central tendency (mean and standard deviation) were also used to analyze the variables. Accordingly, the present study used Pearson correlation to measure the relationships among the variables.

\section{Data Analysis and Presentation}

Fifty (50) questionnaires were issued directly to the respondents. All 50 questionnaires were returned and those questionnaires were checked manually by the researcher in order to assess whether all data had been duly filled by the respondents. The filled up questionnaires were entered into SPSS version 21.0 and the minimum and maximum values were checked. It was confirmed that there were no missing values. As a result the researcher used the data for the data analysis.

\section{Analysis of Demographic Information}

\section{Objective 01}

The first objective of this study is to find out factors influence on employee retention in Rich Light Exports (pvt) Ltd in Anuradhapura District. The factors were as below and the demographic information in Part I of the questionnaire was analyzed through the descriptive statistics using SPSS version 21.0.

\begin{tabular}{|l|c|c|}
\hline Gender & Frequency & Percentage \\
\hline Male & 13 & $26 \%$ \\
\hline Female & 37 & $74 \%$ \\
\hline Total & 50 & $100 \%$ \\
\hline
\end{tabular}

(Source; Survey data, 2020)

The results indicated that the respondents who participated in the study were females (74\%) while the remainders (26\%) were males. The findings showed that the majority of the respondents were females than male respondents in Rich Light Exports (pvt) Ltd in Anuradhapura District.

\begin{tabular}{|l|c|c|}
\hline Age & Frequency & Percentage \\
\hline Between $21-30$ & 32 & $64 \%$ \\
\hline Between $31-40$ & 16 & $32 \%$ \\
\hline 40 above & 2 & $4 \%$ \\
\hline Total & 50 & $100 \%$ \\
\hline
\end{tabular}

(Source; Survey data, 2020)

According to the above table, majority of the sample represented by the age level between $21-30$ years and it is $64 \%$ of the sample. There is $32 \%$ presented age category of 31-40. And also there are low respondents in the age level of above 40 years. Also there are $4 \%$ employees are above 40 year 
Descriptive Statistics for Independent Variables

\begin{tabular}{|l|c|c|}
\hline Variable & Mean & Standard Deviation \\
\hline Motivation & 3.74 & 0.416 \\
\hline Work Environment & 3.69 & 0.525 \\
\hline Primary hygiene factors & 3.74 & 0.524 \\
\hline Secondary hygiene factors & 3.99 & 0.401 \\
\hline Retention & 3.83 & 0.395 \\
\hline
\end{tabular}

(Source; Survey data, 2020)

Above table describes descriptive statistics of responses of respondents related with independent variables of the study. According to the above table, mean value for Motivation indicates that Motivation makes a significant impact to the Retention of apparel sector employees $(\mathrm{M}=3.74 \mathrm{SD}=0.416)$. And in case of Work environment it also shows a low significance than other variables $(\mathrm{M}=3.69, \mathrm{SD}=0.525)$ towards the Retention of apparel sector employees. Mean value of Primary hygiene factors $(\mathrm{M}=3.74, \mathrm{SD}=0.524)$ and Secondary hygiene factors $(\mathrm{M}=3.99, \mathrm{SD}=0.401)$ too are high indicating that both variables are favorably influencing to Retention of apparel sector employees.

The results express that most of the respondents had a common opinion on employee retention and the value is 3.83 . It is not high but slightly high hence organization should develop some strategies to retain the employees.

\section{Results and Findings:}

Objective Two ; "To identify the relationship between motivation and employee retention in Rich Light Exports (pvt) Ltd in Anuradhapura District".

$\mathrm{H}_{1}$ : Motivation will be positively correlated with employee retention

\begin{tabular}{|c|c|c|c|}
\hline & & Employee retention & Motivation \\
\hline $\begin{array}{l}\text { Retention } \\
\text { Motivation }\end{array}$ & $\begin{array}{l}\text { Pearson Correlation } \\
\text { Sig. (2 tailed) } \\
\mathrm{N} \\
\text { Pearson Correlation } \\
\text { Sig. (2 tailed) } \\
\mathrm{N}\end{array}$ & $\begin{array}{c}.631 \\
.001 \\
50\end{array}$ & $\begin{array}{c}.631 \\
.001 \\
50\end{array}$ \\
\hline
\end{tabular}

$* *$ Correlation is significant at the 0.01 level (2-tailed)

(Source: Survey Data,2020)

In order to find out the relationship between motivation and employee retention, the summary results of $\mathrm{H}_{1}$ reported in the above table and it shows that the strength of association between motivation and employee retention is strong $(\mathrm{r}=0.631)$ and that the correlation coefficient is statistically significant different from zero ( $\mathrm{P}<0.001)$. Also, 40\% (0.6312) of the variation in employee retention is explained by Motivational factors. Therefore, the findings conclude that a positive correlation exists between employee retention and motivation, which is when motivation increased, employee retention also increased. Finally, the result confirmed that motivation will positively relate to employee retention which is stated in $\mathrm{H}_{1}$. Therefore hypothesis 1 is accepted.

Objective 03; "To identify the relationship between Work environment and employee retention in Rich Light Exports (pvt) Ltd in Anuradhapura District".

$\mathrm{H}_{2}$ : work environment will be positively correlated with employee retention

\begin{tabular}{|c|c|c|c|}
\hline & & Employee retention & Motivation \\
\hline Retention & $\begin{array}{l}\text { Pearson Correlation } \\
\text { Sig. (2 tailed) } \\
\text { N }\end{array}$ & & $\begin{array}{l}.245 \\
.001 \\
50\end{array}$ \\
\hline
\end{tabular}




\begin{tabular}{|c|c|c|}
\hline Work Environment & $\begin{array}{l}\text { Pearson Correlation } \\
\text { Sig. (2 tailed) } \\
\mathrm{N}\end{array}$ & $\begin{array}{c}.245 \\
.001 \\
50\end{array}$ \\
\hline
\end{tabular}

$* *$ Correlation is significant at the 0.01 level (2-tailed)

(Source: Survey Data, 2020)

In order to find out the relationship between work environment and employee retention, the summary results of $\mathrm{H}_{2}$ reported in the above table and it shows that the strength of association between work environment and employee retention is weak $(r=0.245)$ and that the correlation coefficient is statistically significant different from zero $(\mathrm{P}<0.000)$. Also, 6\% (0.2452) of the variation in employee retention is explained by work environment factors. Therefore, the findings conclude that a positive weak correlation exists between employee retention and work environment, which is when work environment increased, employee retention also increased. Finally, the result confirmed that work environment will positively relate to employee retention which is stated in $\mathrm{H}_{2}$. Therefore hypothesis 2 is accepted.

Objective 04 ; “To identify the relationship between primary hygiene factors and employee retention in Rich Light Exports (pvt) Ltd in Anuradhapura District".

$\mathrm{H}_{3}$ : primary hygiene factors will be positively correlated with employee retention

\begin{tabular}{|c|c|c|c|}
\hline & & Employee retention & Motivation \\
\hline $\begin{array}{l}\text { Retention } \\
\text { Primary Hygiene factors }\end{array}$ & $\begin{array}{l}\text { Pearson Correlation } \\
\text { Sig. (2 tailed) } \\
\mathrm{N} \\
\text { Pearson Correlation } \\
\quad \text { Sig. (2 tailed) } \\
\mathrm{N}\end{array}$ & $\begin{array}{c}.644 \\
.000 \\
50\end{array}$ & $\begin{array}{c}.644 \\
.000 \\
50\end{array}$ \\
\hline
\end{tabular}

**Correlation is significant at the 0.01 level (2-tailed)

(Source: Survey Data, 2020)

In order to find out the relationship between primary hygiene factors and employee retention, the summary results of $\mathrm{H}_{3}$ reported in the above table and it shows that the strength of association between primary hygiene factors and employee retention is strong $(\mathrm{r}=0.644)$ and that the correlation coefficient is statistically significant different from zero $(\mathrm{P}<0.000)$. Also, 41\% $(0.6442)$ of the variation in employee retention is explained by primary hygiene factors. Therefore, the findings conclude that a positive strong correlation exists between employee retention and primary hygiene factors, which is when primary hygiene factors increased, employee retention also increased. Finally, the result confirmed that primary hygiene factors will positively relate to employee retention which is stated in $\mathrm{H}_{3}$. Therefore hypothesis 3 is accepted.

Objective 05 ; “To identify the relationship between Secondary Hygiene Factors and Employee Retention in Rich Light Exports (pvt) Ltd in Anuradhapura District".

$\mathrm{H}_{4}$ : secondary hygiene factors will be positively correlated with employee retention

\begin{tabular}{|c|c|c|c|}
\hline & & Employee retention & Motivation \\
\hline $\begin{array}{l}\text { Retention } \\
\text { Secondary Hygiene factors }\end{array}$ & $\begin{array}{l}\text { Pearson Correlation } \\
\text { Sig. (2 tailed) } \\
\mathrm{N} \\
\text { Pearson Correlation } \\
\quad \text { Sig. ( } 2 \text { tailed) } \\
\mathrm{N}\end{array}$ & $\begin{array}{c}.702 \\
.000 \\
50\end{array}$ & $\begin{array}{c}.702 \\
.000 \\
50\end{array}$ \\
\hline
\end{tabular}

$* *$ Correlation is significant at the 0.01 level (2-tailed)

(Source: Survey Data, 2020)

In order to find out the relationship between secondary hygiene factors and employee retention, the summary results of $\mathrm{H}_{4}$ reported in the above table and it shows that the strength of association between secondary hygiene factors and employee retention is strong $(\mathrm{r}=0.702)$ and that the correlation coefficient is statistically significant different from zero $(\mathrm{P}<0.000)$. Also, $49 \%(0.7022)$ of the variation in employee retention is explained by secondary hygiene factors. Therefore, the findings conclude 
that a positive strong correlation exists between employee retention and secondary hygiene factors, which is when secondary hygiene factors increased, employee retention also increased. Finally, the result confirmed that secondary hygiene factors will positively relate to employee retention which is stated in $\mathrm{H}_{4}$. Therefore hypothesis 4 is accepted.

\section{Conclusion and Recommendations}

\section{Conclusion}

Based on the descriptive analysis, all independent variables are highly affected with the employee retention, motivation, working environment, primary hygiene factors and Secondary hygiene factors. Even though, work environment factors were not that much influence on employee retention and other variables were highly influences on employee retention in in Rich Light Exports (pvt) Ltd in Anuradhapura District. Respondents were gave same opinion on other variable such as, motivation, primary hygiene factors and Secondary hygiene factors. Moreover, primary and secondary hygiene factors were slightly high influence on employee retention because respondents believe that organization provide better training and development, provide opportunities to develop their skills, provide good welfare services to their employees therefore the mean value is (3.74 and 3.99 respectively). Motivation and work environment factors, organization should consider more to retain their more talented employees with in their organization. All variables show high mean value even though they should improve each factor because it is slightly near to moderate value.

To find out the relationship between dependent variable and independent variables, all independent variables such as, motivation, work environment, primary hygiene factors and secondary hygiene factors significantly correlated with employee retention. Therefore, all hypotheses were accepted. According to findings, Motivation positively correlated with employee retention of in Rich Light Exports (pvt) Ltd in Anuradhapura District. Motivation factors such as Team work, Work life balance, Resect and fair treatment, Leave benefits are directly influencing employee retention. Work environment is positive weak relationship between employee retention Based on the analysis of that data; the working environment which was established by organization is also satisfactory level to the employees. Primary hygiene factors make the positive strong relationship between the employee retention in Rich Light Exports (pvt) Ltd in Anuradhapura District. So the primary hygiene factors are directly motivated employee retention when considering the secondary hygiene factors; there is strong positive relationship between employee retention.

\section{Recommendations}

Based on the findings and conclusions of the study, the researcher forwards the following recommendations to the management of the factory. That is to say, the factory management should focus on these factors to maximize employee motivation and retention.

For the enhancement of the employee mindset the researcher suggest these recommendations to overcome relating to the motivation such as competitive advantage is mostly effect with employee motivation these kind of organizations because large number of employees working here and there are lot of employee diversity. Management should give to opportunities for teamwork in that time can earn better productivity and high employee satisfaction. Management must equal and regular pay scale that time employees can understand clearly.

The researcher is suggesting these recommendations for the working environment which was affected positively to employee retention like, Employees are better to provide supportive usage and modern working instruments, Better to introduce more flexible and easiness working instrument to support employees' day to day duties and responsibilities, It is better to establish better health and safety system like keeping proper ventilation, considerable amount of toilet system, establishing fire extinguishers, eliminate the ergonomics, Introduce proper safety awareness to the machine operators, Rotating every single of employees' job role for the betterment of their health and safety, Great advantage of conducting training and development program constantly.

These recommendations are suggesting primary hygiene factors which was affected positively to the employee retention of Rich Light Exports (pvt) Ltd in Anuradhapura District such as, It is better to treat all the employees equally by giving their welfare and the other facilities, All the welfare programs such as transport, meals, medical should be better to conduct equally with the other competitive organizations, better to retain strong relationship between employees and the employer and among the employees at the same time among the employers also, Workers and organization is better to link and have strong impression, All the workers are better to make happy physically and psychologically also, Better to appreciate the employees by offering annual trip, transport services, birthday celebrations party, medical treatment etc.

Finally researcher is suggesting such recommendations secondary hygiene factor which was affected positively retention of employee Rich Light Exports (pvt) Ltd in Anuradhapura District like, All the employees are better to grant equal training 
opportunities to develop their career, Offering considerable amount of mentoring opportunities with competitive industries, Employees are better to enhance their personal and professional career progression within the company. It is better to maintain growth opportunities based on workers' experience level, Employees are better to offer on time promotion and growth opportunities.

\section{References}

Burns, A., \& Bush, R. (2009). Marketing research. 200-231.

Cooper, D., \& Schindler, P. (2003). Business Research Methods International Edition McGraw Hill.

Daniel, T., \& Metcalf, G. (2009). Employee Recognition: Selling, Implementing and communicating the program. Illinois, CH: American Society for Training and Development HR.

Das, B., \& Baruah, M. (2013). Employee Retention’ A Review of Literature. IOSR Journal of Business and Management (IOSR$J B M)$, 14(02), 08-16.

Grensing, L. P. (2000). 'Creative approaches to employee retention SHRM White Paper,(Society for Human Resources Management).

Hee, C., \& Ling, F. (2011). Strategies for reducing employee turnover and increasing retention rates of quantity surveyors. Construction Management and Economics, 1059-1072.

Herman, R. (1999). Keeping good people-Strategies for solving the No.1 problem facing business today.

Herzberg, F., Mausner, B., \& Snyderman, B. (1959). the motivation to work’ New York.

Hokanson, C., Sosa-Fey, J., \& Vinaja, R. (2011). Mitigating the Loss of Knowledge Resulting From the Attrition of Younger Generation Employees.

Kay, B., \& Jordan, E. (1999). Love 'em or lose 'em—getting good people to stay.

McKeen, J., Smith, H., \& Jin, J. (2009). Successful Strategies for IT Staffing Communication for the Association for Information System. Developments in Practice XXXII, 24, 805-820.

Radford, K., \& Chapman, G. (2015). Are All Workers Influenced to Stay by Similar Factors, or Should Different Retention Strategies be implemented' Comparing Younger and Older Aged-care Workers in Australia. 41(1), 58-81.

Robbins, S. (2003). 'Organizational behavior' 11th Ed.

Rose, N., Rendell, P., Hering, A., \& Kliegel, M. (2015). Cognitive and neural plasticity in older adults' prospective memory following training with the Virtual Week computer game Frontiers in human neuroscience. 09, 59.

Ryan, R., Deci, E., \& Connell, J. (1989). Self-determination in a work organization. Journal of Applied Psychology, 74, 580-590.

Samuel, M., \& Chipunza , C. (2009). Employee retention and turnover: Using motivational variables as a panacea. African Journal of Business Management, 3(8), 410-415.

Sandhya, K., \& Kumar, P. (2011). Employee retention by motivation. Indian Journal of Science and Technology, 4(12), 17781782.

Sekaran, U. (2003). Towards a guide for novice research on research methodology: Review and proposed methods. Journal of Cases of Information Technology, 8(4), 24-35.

Smith, G. (2004). Transforming your Workforce from High Turnover to High Retention. 203.

Srinivas, K. (2012). A study on Effectiveness of Training and Development Programs Adopted by KPCL. International Journal of Engineering and Management Research, 2(1). 
International Journal of Scientific and Research Publications, Volume 10, Issue 7, July 2020

ISSN 2250-3153

Sue, S. (2001). Successful Staff Retention in one week.

Varma, S. (2011). Antecedents of employee performance: an empirical investigation in India Employee Relations. 34(02), 177192.

William, B., \& Werther, J. (1996). Human Resource and Personnel Management, 5th Edition . 